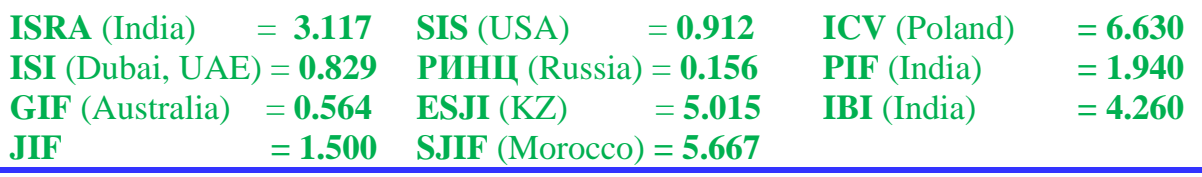

SOI: $\underline{1.1 / \text { TAS }}$ DOI: $\underline{10.15863 / \text { TAS }}$

International Scientific Journal Theoretical \& Applied Science

p-ISSN: 2308-4944 (print) e-ISSN: 2409-0085 (online)

Year: $2018 \quad$ Issue: 12 Volume: 68

Published: $12.12 .2018 \quad$ http://T-Science.org

SECTION 11. Biology. Ecology. Veterinary.

\section{QR - Issue}

QR - Article
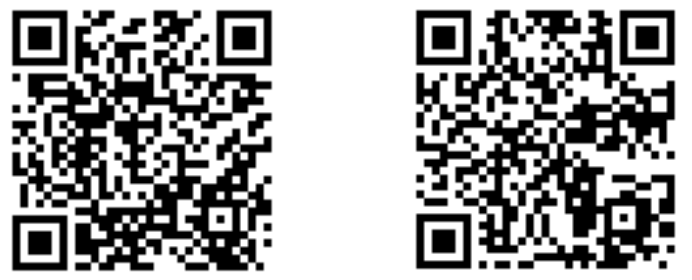

Zhanar Bidakhmet

Departament of Computer Engineering, AIPET

Almaty, Kazakhstan

zhanarbi@rambler.ru

Zh.Zh. Kozhamkulova

Departament of Computer Engineering, AIPET

M.N. Maikotov

Departament of Computer Engineering, AIPET

\title{
INFLUENCE OF ECOLOGY ON HUMAN HEALTH
}

\begin{abstract}
The aim of this work is to study the main factors environmental pollution affecting human health.
Environmental and human health in the world today is in a close relationship. It is proven that a clean environment is essential and of paramount importance for human health.

Environmental degradation leads to an increase in demand for medical services for diagnosis and treatment of diseases associated with exposure to environmental hazards (respiratory diseases, cancer, allergic diseases, etc.).

As a result the negative effects of ecology efficiently affect all the other spheres of human activity.

Key words: Environmental factors, human health, disease, diagnosis, and medicine.

Language: English

Citation: Bidakhmet, Z., Kozhamkulova, Z. Z., \& Maikotov, M. N. (2018). Influence of ecology on human health. ISJ Theoretical \& Applied Science, 12 (68), 11-15.

Soi: http://s-o-i.org/1.1/TAS-12-68-3 Doi: crossef https://dx.doi.org/10.15863/TAS.2018.12.68.3
\end{abstract}

\section{Introduction}

Ecology creates a person who in the last millennium has affected her in a way that simplifies their lives, worked out a mechanism that works tirelessly on his health, and more and more negative.

The atmosphere of every day is becoming more and more polluted, and contributes to this means of transport, as well as the modern industry. Every day in the air get dangerous substances such as manganese, arsenic, selenium, xylene, asbestos, styrene, etc., because the list is endless. When all of these substances enter the body, they can provoke the development of cancer and diseases of the nervous system, because many may have noticed that in recent years' people became more aggressive and unstable.

The problem of environmental pollution fully risen after a XX century. man greatly expanded the number of metals used in them. They began to produce synthetic fibers, plastics and other materials that have properties not only well-known nature, but also harmful to the biosphere organisms. These after use do not enter the natural cycle. Wastes from of industrial activity are increasingly polluting the lithosphere, hydrosphere and atmosphere of the Earth. Adaptive mechanisms of the biosphere cannot cope with the increasing amount of neutralization of harmful substances its normal functioning. In this case the natural ecosystems are experiencing oppression and begin to break down.

Water, which is part of the environment and a source of a full human life. To date, nearly $2 / 3$ of all human diseases in the world arise from the use of ordinary water. Plain water, which should give everyone a full health can lead to the following diseases:

1) Oncological diseases

2) Genetic changes, because of which the children are born with a variety of disabilities.

3) Reduced immunity.

4) Reducing the work of reproductive organs, like the female half and a male.

5) Diseases of internal organs, namely the liver, kidneys and gastrointestinal tract.

This ensures that the environmental impact on human health is similar to the influence of a delayedaction bomb to the world. 


\begin{tabular}{|c|c|c|c|c|c|c|}
\hline \multirow{4}{*}{ Impact Factor: } & ISRA (India) & $=3.117$ & SIS (USA) & $=0.912$ & ICV (Poland) & $=6.630$ \\
\hline & ISI (Dubai, UAI & $=0.829$ & РИНЦ (Russia) & $=0.156$ & PIF (India) & $=1.940$ \\
\hline & GIF (Australia) & $=0.564$ & ESJI (KZ) & $=5.015$ & IBI (India) & $=4.260$ \\
\hline & JIF & $=1.500$ & SJIF (Morocco) & $=5.667$ & & \\
\hline
\end{tabular}

The water and the atmosphere, impact negatively on the food that a person consumes each day. Every year in ordinary products that seemingly should bring only benefits, are finding more and more harmful toxins and other elements that may have a negative impact on human health. Therefore, more and more diseases appear in the world, which are not curable. This once again confirms the negative impact of environmental health.

During the last 50-60 years there is a large-scale environmental pollution by various organochlorine substances that received name - endocrine disruptors. Agency for the US Environmental Protection Agency has identified these substances as "exogenous agents that interfere with the production, release, transport, metabolism, binding, action or elimination of hormones in the body involved in the maintenance of homeostasis and regulation of developmental processes."

Experimental evidence for their effect on the production, release, transport, metabolism, binding of thyroid hormones are given in [11, 34, 35]. To this we must add that the huge number of household chemicals, consisting mainly or partly of toxic substances, and thus directly or indirectly affect the thyroid system, we flooded our lives.

\section{Ecological factors affecting the human organism}

Health is affected by climatic factors, chemical and biological composition of the air we breathe, the water we drink, and a host of other environmental factors.

Environmental factors can have on the human organism the following impact:

- Can favorably influence on the human body (the fresh air, moderate exposure to UV rays help to strengthen our health);

- May act as irritants, thus forcing us to adapt to certain conditions;

- Can trigger substantial structural and functional changes in our organism (for example, dark skin among indigenous inhabitants of the regions with intense by the sun);

- are capable completely exclude our dwelling under certain conditions (a person can not live under water without oxygen).

The huge damage to human health does smoking. Smoker inhales not only the harmful substances, but also pollutes the environment, endanger others. It was found that people who are in the same room with a smoker, inhale even greater pollutant than himself. [7. 251]

The built environment also requires adaptation to itself, which is going through the disease. The cause of disease in this case is the following: lack of exercise, overeating, information abundance, psychoemotional stress.

At present, the effect of these causes in varying degrees, typical of almost all human habitats.

Table 1. Factors influencing health

\begin{tabular}{l|l|l|l|}
$\begin{array}{l}\text { The sphere } \begin{array}{l}\text { of } \\
\text { influence } \\
\text { factors }\end{array} \\
\text { of }\end{array}$ & $\begin{array}{l}\text { Factors } \\
\text { Promote health }\end{array}$ & Deteriorating health \\
\hline $\begin{array}{l}\text { Genetical } \\
(15-20 \%)\end{array}$ & $\begin{array}{l}\text { Healthy heredity. The absence of } \\
\text { morphological and functional prerequisites } \\
\text { for the emergence of diseases }\end{array}$ & $\begin{array}{l}\text { Hereditary diseases } \\
\text { disorders. } \\
\text { predisposition to disease }\end{array}$ \\
\hline $\begin{array}{l}\text { State of } \\
\text { environment } \\
(20-25 \%)\end{array}$ & the & $\begin{array}{l}\text { Good household and industrial conditions, } \\
\text { favorable climatic and natural conditions, } \\
\text { environmentally favorable habitat }\end{array}$ & $\begin{array}{l}\text { Harmful conditions of life and } \\
\text { production, adverse climatic and } \\
\text { natural conditions, violation of } \\
\text { ecological conditions }\end{array}$ \\
\hline $\begin{array}{l}\text { Medical } \\
\text { maintenance } \\
(10-15 \%)\end{array}$ & $\begin{array}{l}\text { Medical screening, a high level of } \\
\text { prevention, timely and comprehensive } \\
\text { medical care }\end{array}$ & $\begin{array}{l}\text { The lack of permanent medical } \\
\text { supervision of the health } \\
\text { dynamics, the low level of } \\
\text { primary prevention, poor health }\end{array}$ \\
\hline
\end{tabular}




\begin{tabular}{|c|c|c|c|c|c|c|}
\hline \multirow{4}{*}{ Impact Factor: } & ISRA (India) & $=3.117$ & SIS (USA) & $=0.912$ & ICV (Poland) & $=6.630$ \\
\hline & ISI (Dubai, UAI & $=0.829$ & РИНЦ (Russia) & $=0.156$ & PIF (India) & $=1.940$ \\
\hline & GIF (Australia) & $=0.564$ & ESJI (KZ) & $=5.015$ & IBI (India) & $=4.260$ \\
\hline & JIF & $=1.500$ & SJIF (Morocco) & $=5.667$ & & \\
\hline
\end{tabular}

Conditions and lifestyle $(50-55 \%)$
The rational organization of life, sedentary lifestyle, adequate physical activity, social and psychological comfort. a complete and balanced diet, lack of bad habits, vale logical education and so forth.
The absence of a rational mode of life, migration, hypo- or hyperdynamia, social and psychological discomfort. poor diet, bad habits, lack of knowledge
With medical and biologic positions the following trends exposed are most influenced by social and of ecological factors.

\section{Formation a healthy lifestyle}

Any State which is aimed at preserving and protecting the health of its citizens. The implementation of this task sees the availability of health services, as well as progress in the life of the various programs on the free implementation of preventive measures for the poor and the privileged categories of citizens.

The state spends stimulating and prohibiting measures, including financial and legislative level. Such measures may include a ban on the production and use of drugs (excluding medical purposes), their use and distribution, are punishable with criminal charges, a ban on the dissemination of advertising for tobacco products and alcoholic beverages, limit their sales in certain places age restrictions on their acquisition, increase in excise duties, promotion of healthy lifestyle promotion in the media, the introduction of educational programs of special courses aimed at promoting healthy lifestyles [10].

Most of the work on formation of healthy way of life rests on the shoulders of public health, but without government support - both legally and financially - this program is being implemented very slowly.

In this direction on the part of health care should be carried out activities to provide advisory assistance to the population in medical institutions.

An important role has a connection to the process of formation of healthy life-style media, which should actively carry out propaganda among the population about the negative attitude to people leading unhealthy lifestyles and, on the contrary, encourage and promote physical culture and sports, a positive attitude and cultivation physically beautiful and a healthy body, as well as the motivation to give up bad habits. In terms of the latter, it should also be noted the restrictive measures imposed by the state [11].

In the narrowly biological sense we are talking about human physiological adaptation possibilities to environmental effects and changes in the state of the internal environment. The authors who write on this subject include "healthy lifestyle" different components, but most of them consider basic:

- Mannerliness from early childhood healthy habits and skills;

- Environment: safe and favorable for living, the knowledge about the influence of the surroundings on health;

- No smoking, drug use, alcohol use.

- Food: moderate, corresponding to the physiological characteristics of a specific person, the awareness of the quality of used products;

- Movement: a physically active life, including special physical exercises, taking into account the age and physiological characteristics;

- Hygiene organism: the observance of rules of personal and public hygiene, knowledge of first aid skills; tempering.

In the physiological state of a person is greatly influenced by its psycho-emotional state, which depends, in turn, from his mental facilities. Therefore, some authors also highlight the following additional aspects of a healthy lifestyle:

-emotsional health: mental hygiene, the ability to cope with their own emotions, problems;

- Intellectual well-being: a person's ability to recognize and use the new information to the best action in the new circumstances.

Positive thinking, spiritual well-being: the ability to establish truly meaningful, constructive life goals, to strive for and achieve them. Optimism. Some researchers identify as "social wellbeing" - the ability to interact with others. 


\begin{tabular}{llllll} 
& ISRA (India) $=\mathbf{3 . 1 1 7}$ & SIS (USA) $=\mathbf{0 . 9 1 2}$ & ICV (Poland) & $=\mathbf{6 . 6 3 0}$ \\
Impact Factor: & ISI (Dubai, UAE) $=\mathbf{0 . 8 2 9}$ & PUHL (Russia) $=\mathbf{0 . 1 5 6}$ & PIF (India) & $=\mathbf{1 . 9 4 0}$ \\
& GIF (Australia) $=\mathbf{0 . 5 6 4}$ & ESJI (KZ) & $\mathbf{5 . 0 1 5}$ & IBI (India) & $=\mathbf{4 . 2 6 0}$ \\
& JIF & $\mathbf{1 . 5 0 0}$ & SJIF (Morocco) $=\mathbf{5 . 6 6 7}$ & & \\
\hline
\end{tabular}

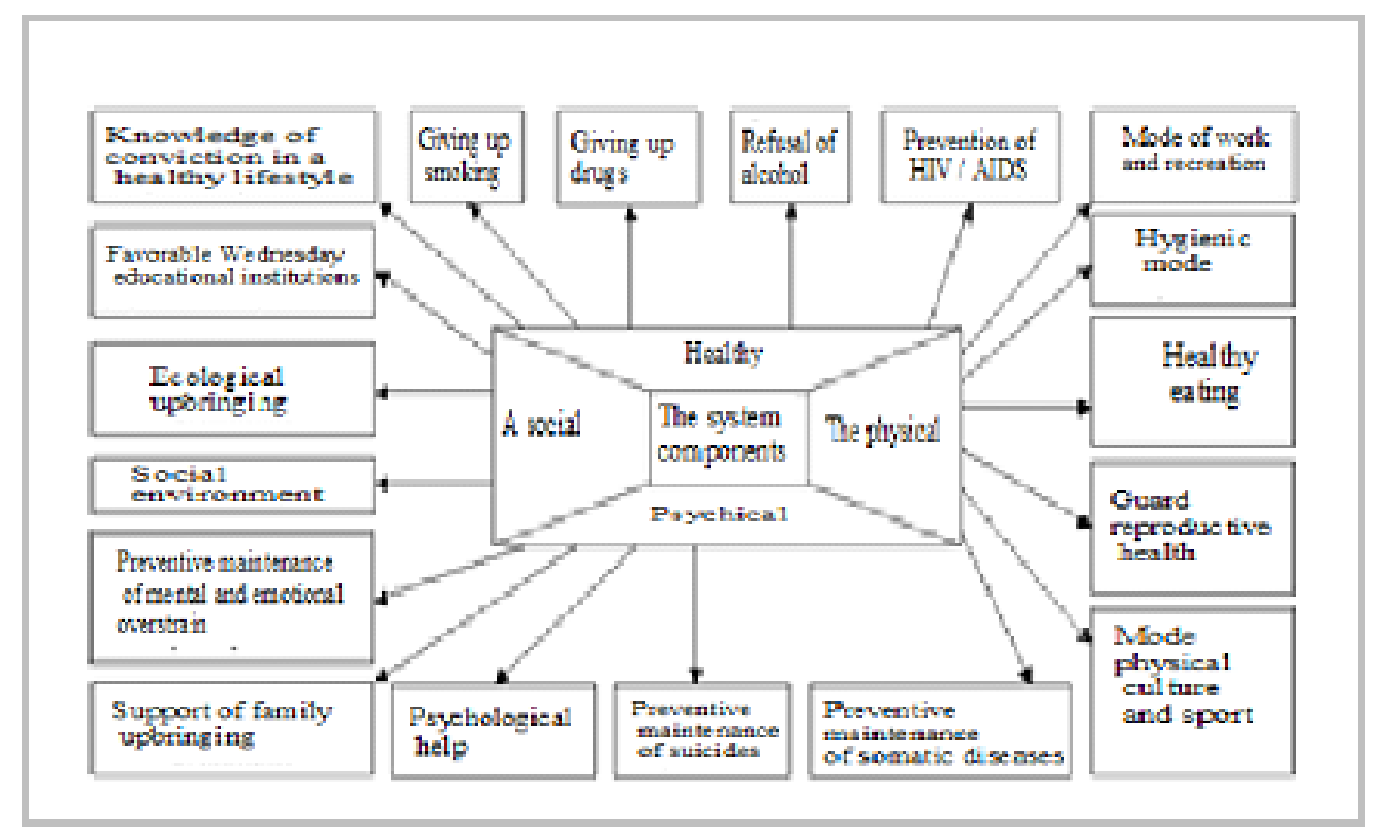

Figure 1. The various components of "healthy lifestyle" system.

You can define the following basic directions in activity on formation of a healthy lifestyle:

- The creation of advocacy system for raising the level of knowledge of all categories of the population about the negative health effects of risk factors, the possibility of loss.

- The second important area of healthy lifestyle - so-called "health education."

- Measures to reduce the prevalence of smoking and tobacco consumption, reduce alcohol consumption, drug use prevention.

- Urge the population to active living, physical culture, sport and tourism, improving the availability of these types of recovery.

Health promotion now requires more material and labor costs. This leads to the fact that health is in series with the other economic categories. For its normal reproduction requires a set of measures designed to ensure the safe development of production and the restoration of the lost health indicators.

WHO studies in this area have led to the identification of the following statistical figures. Human Health on $50-55 \%$ depends on lifestyle, on $20-23 \%$ - of the hereditary factors of $20-25 \%$ - from environmental factors and only 8-10\% - from medicine and health care.

\section{Conclusion}

In recent years, an increasing number of diseases related to environmental pollution. The negative effects of environmental impact on all other areas of human activity.

Trying to create comfortable conditions for its existence, we spoil all that is given to us by nature. Because human inventions and are acid rain due to the atmosphere human inventions and negative elements into the water because of the inventions human foods lose their quality.

World experience shows that the most important factors affecting the health of the population - this is the state measures to prevent diseases. A first step should be a step aimed at ensuring environmental safety.

For a long time people perceive nature as a pantry, from which you can draw on to infinity. This has led today to the threat of environmental catastrophe. It is necessary to protect the world in which we live.

Today the problem ecology must be solved at the planetary level. This union of countries, government programs, non-governmental organizations, mannerliness in the family.

The main sources of pollution - cars, industry and power plants. 


\begin{tabular}{lllllll} 
& ISRA (India) & $=\mathbf{3 . 1 1 7}$ & SIS (USA) & $=\mathbf{0 . 9 1 2}$ & ICV (Poland) & $\mathbf{= 6 . 6 3 0}$ \\
Impact Factor: & ISI (Dubai, UAE) $=\mathbf{0 . 8 2 9}$ & PUHL (Russia) $=\mathbf{0 . 1 5 6}$ & PIF (India) & $=\mathbf{1 . 9 4 0}$ \\
& GIF (Australia) & $=\mathbf{0 . 5 6 4}$ & ESJI (KZ) & $\mathbf{5 . 0 1 5}$ & IBI (India) & $\mathbf{= 4 . 2 6 0}$ \\
& JIF & $\mathbf{1 . 5 0 0}$ & SJIF (Morocco) & $=\mathbf{5 . 6 6 7}$ & & \\
\hline
\end{tabular}

\section{References:}

1. Belik, E. V., \& Vodolazskaya, T. I. (2004). Nature. (p.896). Moscow: JSC "Bao-Press".

2. Denisov, V. V. (2004). Ecology: Textbook, - 2 ed. Revised. and ext. (p.672). Moscow: ECC "March".

3. Karlovic, I. (2005). Geoecology: A textbook for high school. (p.512). Moscow: Academic Project, Alma Mater.

4. Novikov, Y. (2002). Ecology, Environment and People: A manual for students - 2 ed. Revised. and ext. (p.560). Moscow: FAIR PRESS.

5. Nikanorov, A. M, \& Khoruzhaya, T. A. (2002). Ecology. (p.320). Moscow: Publishing house PRIOR.

6. Petrov, K. M. (2002). General ecology. The interaction of society and nature: Textbook for high schools - 3rd ed. Revised. and ext. (p.356). $\mathrm{SPb}$.: Chemistry.
7. Protasov, V. F. (2003). Environment, health and environmental protection in Russia. (p.345). Moscow: Publishing house of the Finance and statistics.

8. Butaev, A. M. (2012). Endemic goiter and its prevention methods from the point of view of ecology. Vestnik. Dagest. scientific. center.

9. Martynenko, A. V., et al. (1988). Formation of a healthy way of life of young people. M .: Medicine.

10. Izutkin, D. A. (1984). Formation of a healthy lifestyle. The Soviet health care, №11.

11. Yablokov, A. V. (2007) Human health and the environment. Moscow.

12. Lisitsyn, Y. P. (1986). Word health. Moscow. Free electronic encyclopedia / Healthy lifestyle. Retrieved 2018, from http://ru.wikipedia.org 